\title{
CRISTIANAS, JUDÍAS Y MUSULMANAS EN LA CIUDAD DE HUESCA A FINALES DE LA EDAD MEDIA
}

\author{
CHRISTIAN, JEWISH AND MUSLIM WOMEN IN HUESCA DURING \\ THE LATE MIDDLE AGES
}

\begin{abstract}
Resumen: Cristianas, judias y musulmanas en la ciudad de Huesca a finales de la Edad Media es un trabajo de historia urbana redactado desde una perspectiva de género que analiza la presencia, ámbitos de actuación, relaciones y actividades de las oscenses de finales del Cuatrocientos. Se fundamenta en documentación archivística inédita, especialmente protocolos notariales, y se estructura en cinco grandes apartados, en los que se analizan las etapas de la vida de las mujeres de las tres culturas así como la participación femenina en el mundo laboral y la economía urbana. La religiosidad de todas ellas se analiza también a través de testamentos y registros iconográficos.
\end{abstract}

Palabras clave: Historia de las Mujeres; Reino de Aragón; Huesca; siglo xv; Multiculturalidad

\begin{abstract}
Christian, Muslim and Jewish Women in the City of Huesca during the Late Middle Ages is a work of urban history written from a gender perspective that analyses the presence, spheres of activity, relations and duties of these women in the $15^{\text {th }}$ Century. The dissertation is based on unpublished archive documentation, and is structured in five big sections, which analyze the stages of women lives', from their education to their death. Similarly, their participation in the labour sphere is analysed, as well as their religiosity through wills and iconographic registry that have lasted to our days.
\end{abstract}

Key words: Women's History; Kingdom of Aragon; Huesca; 15 $5^{\text {th }}$ Century; Multiculturalism. 


\section{Introducción ${ }^{1}$}

En octubre de 1928 Virginia Woolf fue invitada a pronunciar dos conferencias en sendos colegios femeninos de la Universidad de Cambridge. De aquellas jornadas en las que fue convocada para enseñar a «mujeres jóvenes, hambrientas pero valerosas, inteligentes pero destinadas a convertirse en maestras de escuela por docenas», según anotó en su diario, nació A Room of one's own, «Un cuarto propio», uno de los libros fundamentales del pensamiento feminista del siglo xx. En ese volumen, Woolf recomendaba a las jóvenes que tuvieran un cuarto propio, un espacio en el que poder dedicarse a su labor intelectual con privacidad y autonomía, con una cerradura en la puerta, escribe, y quinientas libras anuales para su manutención, o, más bien, su independencia, pues esa cantidad les permitiría trabajar en tareas que las realizasen y que les reportasen felicidad. Como llega a decir en un momento de la obra, «el dinero dignifica lo que, si no se paga, es frívolo» (Woolf, 2003: 96).

En aquellas conferencias, y posteriormente en el texto de Un cuarto propio, Woolf reflexionaba sobre la función de espejo mágico y magnificador que las mujeres habían sido para los hombres a lo largo de la Historia, y la necesidad de reajustar la óptica y describir con precisión la realidad. La motivación de la autora británica y su aguerrida defensa de lo que después se daría en llamar estudios de género, sumados a la financiación concedida para mi proyecto investigador por el Gobierno de España, legitimaba, en cierta manera, mi Tesis Doctoral, destinada a estudiar a otras mujeres valientes, hambrientas e inteligentes como las que inspiraron a Woolf: en mi caso, a las cristianas, judías y musulmanas de la ciudad de Huesca a finales del siglo xv. ${ }^{2}$ A lo largo de sus páginas Woolf se pregunta cómo vivían las mujeres del común de la Inglaterra de los siglos XVI o XVIII, qué ocurría con aquellas que escribían, pintaban, o, simplemente, tenían que sacar adelante sus hogares. Ese reajuste de la mirada

1 El presente artículo es una adaptación del texto pronunciado en la defensa de mi Tesis Doctoral, dirigida por la Dra. María del Carmen García Herrero, Catedrática de Historia Medieval de la Universidad de Zaragoza, que se celebró el 14 de diciembre de 2015 ante un tribunal compuesto por el Dr. José Ángel Sesma Muñoz, de la Universidad de Zaragoza; la Dra. Montserrat Cabré i Pairet, de la Universidad de Cantabria y la Dra. Martine Charageat, de la Universidad de Burdeos, quienes le concedieron la calificación de sobresaliente cum laude así como la mención de calidad europea. Ficha TESEO https:// www.educacion.gob.es/teseo/mostrarRef.do?ref=1193439. La autora ha recibido también el Premio Extraordinario de Doctorado de la Universidad de Zaragoza del curso 2015-2016.

2 La financiación estatal se materializó en forma de una Beca de Formación de Personal Investigador vinculada al Proyecto I+D+I HAR2008-02512, dirigido por la Dra. María del Carmen García Herrero, que recibí en septiembre de 2009 y al que me incorporé entonces. 
hacia el pasado y hacia el presente que proponía y con la que fantaseaba la escritora británica es la motivación fundamental de esta Tesis, con la que espero y confío en haber contribuido, mínima y humildemente, al avance del conocimiento. Como señala Nuria Varela, «el trabajo feminista de los últimos años ha proporcionado material suficiente como para rastrear la historia escondida y silenciada y recuperar los textos y las aportaciones del feminismo durante todo este tiempo. Ha sido tan beligerante el ocultamiento del trabajo feminista a lo largo de la historia que (...) el trabajo de recuperación de nuestra historia añadirá a la genealogía del feminismo nombres, acciones y textos desconocidos hasta ahora» (Varela, 2011: 14-15). Es, pues, a esta genealogía del feminismo a la que Cristianas, judías y musulmanas en la ciudad de Huesca a finales de la Edad Media aspira a contribuir desde sus páginas, presentando modelos femeninos activos y empoderados de su tiempo.

\section{Fuentes, metodología y objetivos}

Cristianas, Judías y Musulmanas en la ciudad de Huesca a finales de la Edad Media analiza, desde una perspectiva de género, la plural sociedad oscense de finales del Cuatrocientos, sus leyes y costumbres, estableciendo un diálogo entre las visiones teóricas y los datos empíricos. El trabajo pretende ser un estudio intercultural, que se sirve de la excepcional situación de la Península Ibérica en la transición de la Edad Media a la Moderna y de la coexistencia de las tres culturas en una ciudad de tamaño medio, como Huesca, para tratar a las mujeres que la habitaron como un todo, en un gendered context, a decir de Elisheva Baumgarten, (Baumgarten, 2008: 214) y no como minorías separadas o excluyentes, tal y como se había venido realizando en la historiografía peninsular (Morant et al., 2005). Hasta ahora no se han publicado apenas análisis de las fuentes inéditas centrados en la coexistencia de las mujeres de las tres religiones, pues los trabajos que han abordado conjuntamente a judías, musulmanas y cristianas han utilizado fuentes editadas y han tendido a centrarse en personajes históricos concretos de diferentes siglos, trazando esencialmente semblanzas biográficas (Fuente, 2006). En otros lugares del continente, como Perpiñán, sí se han realizado esfuerzos en la dirección que se propone en esta Tesis Doctoral, pero con fuentes algo diferentes a las aquí utilizadas (Winer, 2006). Cabe señalar ahora, sin embargo, que los estudios sobre las mujeres medievales del Reino de Aragón -fundamentalmente centrados en las cristianas, judías y conversas zaragozanas - han ido adquiriendo pujanza y un lugar relevante dentro del panorama nacional e internacional en 
los últimos veinte años, con figuras tan destacadas como María del Carmen García Herrero, y son una referencia y un modelo excelente de aproximación historiográfica.

No obstante, hasta la fecha carecíamos de un estudio de conjunto que analizase la realidad de las mujeres de las tres religiones en un espacio y tiempos concretos, y es nuestra pretensión presentar este para la ciudad de Huesca, siempre en la medida de nuestras posibilidades y con los fondos disponibles a nuestro alcance, que configuran un corpus inédito y extenso. Huesca es un observatorio documental privilegiado de la presencia y actividad de cristianas, judías y musulmanas, que hasta ahora permanecía casi inexplorado, pues los esfuerzos investigadores más recientes se habían dedicado al estudio de las élites políticas y el gobierno urbano (Iranzo, 2005).

Así, cabe reconocer que entre los objetivos de la Tesis, que es fundamentalmente un trabajo de exhaustiva investigación archivística, se cuentan el examen de las relaciones familiares de los diversos grupos sociales en las tres religiones y los roles desempeñados por las mujeres en las expectativas, actitudes, comportamientos y estrategias de cada uno de estos grupos. Se trata de reconstruir el sistema de género que tuvo lugar en la Huesca de finales de la Edad Media para observar cómo el rango, la edad y el estado civil determinaban las opciones legales y económicas de las mujeres y entender, así, las vidas de las cristianas, judías y musulmanas. Debe señalarse además que, como es bien sabido, en la Europa medieval la religión fue un factor básico de organización en torno al cual se constituyeron las unidades sociales. La religión, casi más allá que la capacidad económica y la clase social, determinaba la pertenencia a una mayoría o una minoría, como también prefijaba el género, y son categorías imprescindibles para el análisis. Sin embargo, en ocasiones, las oscenses trazaron redes relacionales sin importar en exceso la religión de cada una de ellas a la hora de afrontar proyectos y negocios o de prestarse ayuda mutua, cuidados y atenciones, cuestiones que quedan demostradas a través de las historias de vida que he elaborado de algunas de las protagonistas de este trabajo, así como en las disposiciones testamentarias o en los enlaces matrimoniales, cuyas estrategias permitieron en ocasiones consolidar linajes, afianzar dominios e incrementar patrimonios (Pérez, 2014: 217-240).

Para alcanzar estos objetivos, la Tesis Doctoral plantea un esquema que casi podría calificarse de orgánico, pues se ha adaptado a los hallazgos documentales y al flujo de información extraída de los mismos con el objetivo de recoger el relato más completo tanto de las trayectorias vitales como del 
contexto socioeconómico de las mujeres de las tres culturas de Huesca. La Tesis Doctoral se inicia con un somero estado de la cuestión sobre la ciudad de Huesca, enclave históricamente significativo del Reino de Aragón. Huesca era, como todo el Occidente medieval cristiano y feudal, un espacio mayoritariamente rural. Ya desde el siglo XII la ciudad forma parte de la red de las villas y urbes que vertebran la ordenación territorial de Aragón. Al igual que otros puntos del reino como Jaca, Tarazona, Ejea, Daroca o Albarracín, Huesca «sirve como enlace entre la economía agrícola de los valles y la ganadera de las montañas, organiza los intercambios mercantiles interiores y se configura en punto intermedio para el tráfico de mercancías que traspasaba fronteras. (...) Su privilegiada ubicación, en la rica comarca del Somontano y en el eje de comunicación Cantábrico-Mediterráneo, la convirtió desde la Plena Edad Media en una ciudad-mercado siempre en una proyección modesta, circunscrita al ámbito comarcal y con una dependencia a las actividades agropecuarias o afines del entorno rural» (Sesma, 2005: 5).

Posteriormente, se incluye un sucinto repaso a la corriente historiográfica en la que se enmarca, la Historia de las Mujeres. La producción científica es tan amplia - casi podría decirse inabarcable-, que se ha optado por citar al comienzo de cada capítulo los títulos más destacados de la bibliografía según la temática referida. Lo cierto es que redactar un trabajo como este, de Historia de las Mujeres de la Península Ibérica, en 2015, supone contar con una amplísima bibliografía, un mimbre firme y seguro, que permite avanzar por comparación y por oposición, y que se construye desde los estudios pioneros redactados en la década de los setenta y los ochenta del siglo xx, hasta las investigaciones más recientes y específicas, que permiten analizar los comportamientos y tendencias observados entre las cristianas, judías y musulmanas de Huesca y las mujeres, fundamentalmente las cristianas, de otras partes de la Península o de otros lugares europeos, especialmente para lo referido a las judías, tan bien estudiadas las del territorio askenazí (Baumgarten, 2004, 2008; Klein, 2007), o, para el caso de las musulmanas, las provenientes del norte de África (Marín, 2000, 2002, 2005; Shatzmiller, 1994).

Esta Tesis Doctoral se fundamenta, como señalábamos arriba, en un exhaustivo trabajo archivístico, centrado especialmente en los fondos de protocolos notariales conservados en el Archivo Histórico Provincial de Huesca. Para la segunda mitad del siglo xv, marco cronológico del trabajo, el Archivo conserva 350 volúmenes, que suman un total de 45.514 folios, según los datos proporcionados por el propio centro. Se han vaciado de forma intensiva los 
protocolos, excepto aquellos que por su mal estado de conservación no se pudieron consultar en formato físico ni electrónico. Además de los protocolos notariales, se revisaron también los llamados Papeles de Justicia, que relatan los procesos habidos ante el Justicia o su Lugarteniente, así como los que tienen lugar ante instancias auxiliares, un fondo aparentemente menor pero de gran interés conservado en ese mismo archivo. De igual manera, en el Archivo Municipal de Huesca consultamos los Libros de Actas de la ciudad, que recogen las minutas de las reuniones del Concejo, que contienen sugerentes noticias. Además, los Procesos de Inquisición en los que se vieron implicadas mujeres oscenses y que se custodian en el Archivo Histórico Provincial de Zaragoza también me han sido de gran utilidad para entender la religiosidad de las conversas y sus relaciones con judías y cristianas.

Una parte sustancial del fruto de este trabajo de investigación se pone de manifiesto en el apéndice documental, conformado por 111 documentos, de los cuales 107 permanecían inéditos hasta ahora. En él se incluyen instrumentos de naturaleza variada: capitulaciones matrimoniales, testamentos, contratos, compraventas, firmas de moza, noticias extraídas de los Libros de Actas de la ciudad, informaciones recogidas por los notarios del Concejo, encargos artísticos y cartas públicas de muerte. Los documentos de naturaleza judicial —arbitrajes, sentencias, edictos inquisitoriales - complementan el panorama temático que se aborda en la Tesis, y permiten comprender y contrastar lo manifestado en el cuerpo del trabajo. En el apéndice se transcriben otros documentos menos habituales, como los perdones conyugales, además de una carta pública de separación de cuerpos y un contrato de amancebamiento, entre otros. Las mujeres de las minorías religiosas quedan representadas notablemente en el apéndice, en el que se incluyen la mayoría de las noticias inéditas halladas sobre ellas, desde las cartas de procuración de las judías a los documentos de naturaleza económica emanados del quehacer cotidiano de las musulmanas.

Respecto a la naturaleza de las fuentes, pese a que el objeto de estudio son las mujeres de las tres culturas, cabe reconocer que esta Tesis se sustenta en fuentes cristianas. En primer lugar, porque son la inmensa mayoría de las conservadas; en segundo, por la inevitable barrera del idioma - su autora no lee hebreo ni árabe, idiomas en los que, por otro lado, apenas se conservan documentos-; y, en tercero, porque la presencia de mujeres de todas las grandes religiones en las fuentes cristianas permite establecer un diálogo entre todas ellas y observar cómo se relacionaban unas y otras. Al reparar en que los grupos diferentes funcionan de manera muy similar las preguntas histo- 
riográficas cambian, pues debemos formularnos nuevas cuestiones basadas en lo que sabemos de cada comunidad, explorar a las otras y regresar a nuestras fuentes con nuevos conocimientos e interpelaciones. Es interesante historiográficamente, además, ponderar la presencia o ausencia de unas y otras en la documentación, pues permite reflejar con mayor precisión el peso de unos grupos y otros en el entramado urbano oscense. Los silencios, en casos como este, resultan de lo más elocuentes.

\section{Hipótesis y hallazgos}

Para detallar las hipótesis y hallazgos de Cristianas, judías y musulmanas en la ciudad de Huesca a finales de la Edad Media seguiré el esquema de la propia Tesis, que recorre la vida de las mujeres y su participación en la economía o su relación con el marco jurídico existente.

Así pues, comenzando por la infancia y la juventud, y haciendo nuestras las palabras de Gerda Lerner, puede decirse que históricamente, la educación ha servido para formar a las personas en las habilidades específicas que de ellas necesitaba la sociedad. Durante milenios, la educación se impartía en la familia bajo la forma de aprendizaje. «Los recursos y las oportunidades en este sistema educativo se distribuían en función de la división sexual del trabajo, y estaban diseñados para encajar a niños y niñas en su rol sexuado. Las niñas, a menudo, adquirían habilidades que, aunque asignadas según la división de género, les equipaban con el conocimiento necesario para sobrevivir en el caso de quedarse viudas o solteras» (Lerner, 1993: 22-23). La búsqueda de esos aprendizajes brinda uno de los hallazgos de este trabajo, la certificación documental de la existencia en Huesca de una escuela gestionada por una mujer, Elvira de Pomar, señora de Alerre, al menos desde 1463. El caso de Elvira de Pomar es especialmente relevante además por su cronología, puesto que permite documentar una escuela por primera vez en el Reino de Aragón y adelanta, en algo más de veinte años, el hallazgo de la senyora maestressa del listado de parroquianos de San Gil incluía en 1485 y al maestro de ninyos que el Fogaje de 1495 ubicaba en Barbastro, únicos casos documentados hasta ahora en Aragón por María del Carmen García Herrero (García, 1990: I, 125). Pero fuera de este espacio de formación excepcional dirigido o patrocinado por la señora de Alerre, cristianas, judías y musulmanas aprendían con sus madres y en el ámbito doméstico, como afirmaba Lerner, los conocimientos necesarios para gestionar, en un futuro, sus propios hogares, bien fueran los quehaceres 
de una casa, bien la gestión de un hogar de mayor tamaño y presupuesto con personas a su cargo, en el caso de las jóvenes de más alta extracción social.

El segundo de los itinerarios formativos de las muchachas oscenses era el servicio doméstico. Mediante las llamadas firmas de moza, de las que la documentación oscense no conserva un número muy elevado, muchas de las niñas y jóvenes de clases bajas se incorporaban al servicio como lavanderas, fregonas o recaderas, y a la vez que adquirían la formación necesaria para el desempeño de la tarea que les había sido encomendada, que se convertiría en su oficio en el futuro, este trabajo les reportaba el capital suficiente para acceder al mercado matrimonial.

Por otro lado, dada la escasez de documentos relativos a estos periodos iniciales de la vida, para estudiar la infancia y la juventud de las oscenses contamos con el soporte teórico de tratados, manuales y libros de pensamiento de las tres grandes religiones. Aunque son numerosas las fuentes literarias conservadas, destacaré una por cada grupo religioso de las utilizadas: en el Llibre de les dones de Francesc Eiximenis, el Sefer Hasidim y el Compendio de Medicina de Ibn Habim se periodiza la vida femenina en bloques que parecen determinados por la disponibilidad sexual de las mujeres. A estos autores medievales las mujeres les interesaban, a grandes rasgos, en tanto en cuanto debían ser criadas o debían dedicarse a la crianza. Las niñas y jóvenes, podría decirse, pasan de estar al cuidado de sus madres a ser madres, tarea para la cual son formadas y preparadas en los estadios iniciales de sus vidas, y que supone, para la mayoría de ellas, un momento crucial. La maternidad es, pues, un hecho cultural y político que justifica y estructura la sociedad patriarcal.

El embarazo y la crianza dejan un rastro documental interesante en múltiples niveles, que de nuevo une y separa a las oscenses. La crianza se afronta de maneras diferentes según la religión, y es por eso por lo que las obligaciones maternales no son las mismas para todas las oscenses. Judías y musulmanas podían, por ejemplo, renunciar a la crianza de sus hijos e hijas, como hizo la judía Soli Carnerón en 1486. A Soli, aún con la mishná - la ley- de su lado, su familia política persiguió tras negarse a amamantar al hijo que tuvo con Salomón Çurí, de quien había enviudado antes del nacimiento del pequeño (Benedicto, 2009: 499-501; más sobre él en Pérez, 2015: 85-88). Las musulmanas, por su parte, tenían y tienen el derecho a ser compensadas con un salario o rida por los trabajos que suponen la lactancia y la crianza (Zomeño, 2000: 256-259), fenómeno que también se documenta entre las cristianas, como se pone de manifiesto gracias al acuerdo firmado en 1484 entre Caterina de Val, 
viuda de Juan de Orduña, y su suegro, para que la viuda pudiera «lactar, criar y alimentar» a Johanico y Martinico, sus hijos. El abuelo de los pequeños reconoció ante el notario Martín de Almorabet que Caterina tenía que «posar muchos trabajos y bienes» para sacar adelante a los niños, por lo que se le concedía la propiedad del peculio de su marido, no sólo el usufructo, excepto las casas en las que habitaba junto a los pequeños, aportando así un nuevo documento a este interesante fenómeno de la lactancia materna remunerada (García y Pérez, 2017).

Por su parte, la lactancia mercenaria, una práctica común aunque no masiva en la Baja Edad Media aragonesa, apenas deja rastro documental en Huesca. Mientras en otras ciudades, como Zaragoza, se conservan contratos de nodrizaje, el reducido tamaño de esta urbe y la facilidad para cerrar los acuerdos de viva voz causan el efecto contrario en la capital oscense. En las aproximadamente tres mil fichas que componen la base de datos de esta Tesis Doctoral no consta un solo contrato de nodriza, y apenas se han hallado menciones a estas profesionales más allá de legados puntuales en los testamentos. Sin embargo, no es razonable pensar que no hubiera nodrizas en Huesca, siendo la hipótesis más plausible la falta de costumbre de poner por escrito determinados contratos, llevados a cabo probablemente de manera más informal.

Como los propios Fueros de Aragón reconocían, la obligación de cuidado de los padres también recaía, en ocasiones, sobre las hijas. En las páginas de Cristianas, Judías y Musulmanas aparecen mujeres como María de Santa Cruz, quien en su extenso y emotivo testamento, que se incluye en el apéndice, se ocupa de su padre, un anciano minusválido y dependiente para el que garantiza la mejor de las atenciones hasta el final de sus días:

E veyendo en la salut del dito mi padre que mientre viva sia servido e le sia ministrado cumplidament todo lo necessario, rogando e encargando al dito Gil d'Estallo, marido mio, que por reverencia de [tachado: la passion de nuestro senyor] Dios tienga al dito mi padre en su casa e en su // vivanda e por amor mio al qual dito mi padre con los bienes mios pertenescientes a la dita mi anima, heredera suso dita, faga servir e dar e ministrar cumplidament al dito mi padre el comer, bever, vestir e calçar e de tenerlo sano e enfermo durant su vida e darle liberament todas las cosas neccesarias pora sustentacion de su vida, por manera que en aquello no le fallesca res ni cosa alguna tanto quanto vivira, fasta que lo haya feyto sepultar do a el sera visto, de manera que sia total descargo de mi anima peccadora. E que por ninguna persona no le pueda seyer tirado si aquel le plazera tener que de los ditos mis bienes se pague cumplidament a su voluntat \lo razonable/ e segunt a su buena consciencia sera visto. Et si al dito Gil de Stallo, marido mio, // no le 


\begin{abstract}
plazera aquel tener ni receptar, que en aquel caso por los ditos mis spondaleros sia el dito mi padre comendado ad alguna fiel e buena persona, que del con diligencia e cura le sia ministrado e feyto el servicio e las cosas sobreditas cumplidament, pagandole condecentment de los ditos mis bienes durant la dita su vida. Et quando sera finida la vida del dito mi padre, si de mis bienes hi sobrara pora fazer aniversario o aniversarios, quiero e ordeno que por mis spondaleros infrascriptos sian conprados en lugar o lugares tutos e seguros, los quales mis aniversario o aniversarios se hayan a celebrar e fazer le se celebren e fagan/ en la Seu de la dita. ${ }^{3}$
\end{abstract}

Las muestras de amor familiar no acaban en María de Santa Cruz. Sabemos gracias a las noticias recogidas en los libros de Actas que el Hospital de Nuestra Señora de la Esperanza de Huesca cumplía la función de orfanato (Pérez, 2013a: 304). Las madres en apuros económicos o circunstancias vitales complicadas, como la atravesada por Blanca de Ezpalau, una conversa a quien el portero del convento de franciscanos de Huesca dejó embarazada, podían acudir a la institución asistencial y entregar a las criaturas, facilitándoles así, quizá, un futuro mejor y evitando soluciones más radicales como el infanticidio (Pérez, 2014: 222-223).

He hallado otros documentos de padres preocupados por sus hijas «accidentadas» como María, la hija del ciudadano oscense Bernardo de Sabayés, para quien él dispone en su testamento, dictado en 1464, manutención vitalicia, o Martinica, la hija bastarda del mercader Bernart de Luch, quien al ver acercarse el final de su vida, encomendaba a la pequeña a sus propios padres en un documento fechado un año antes. En cambio, otras mujeres como Violante de Lobato negociaron compensaciones económicas por cuidar a sus madres y a sus hijas, pese a que era una norma recogida por los Fueros de Aragón.

Ahora bien, la trayectoria de las oscenses no puede estudiarse sin prestar atención a una institución fundamental como el matrimonio, y a la que se dedica buena parte de la Tesis Doctoral. En la Edad Media el matrimonio cristiano no se constituía o celebraba en un único acto, sino en varios - generalmente entre dos y tres- (García, 1990; Gaudemet, 1993). Así, a las promesas matrimoniales o palabras de futuro le seguían las palabras de presente, el verdadero acto con valor constitutivo de la unión. Estas palabras, que leemos y casi escuchamos en las fórmulas que los documentos recogen y reproducen, eran pronunciadas ante testigos y familiares y, en ocasiones, un notario. La 
confusión existente y la lucha por el monopolio jurisdiccional entre la Iglesia y las autoridades civiles se reflejan tanto en el texto como en el apéndice, en el que se incluyen ejemplos de todas las formas posibles de organizar la convivencia. Las tipologías del matrimonio cristiano bajomedieval son analizadas y contrastadas documentalmente con ejemplos de los diferentes estratos de la sociedad oscense. Promesas matrimoniales como la de Toda los Royos y Guillem de Claragos, quienes en un breve documento redactado en 1458 daban fe de sus planes y plazos para contraer matrimonio. Su enlace se regiría por capitulaciones dictadas mediante arbitraje, otra de las fórmulas en las que las mujeres, a través de figuras como las de las árbitras Leonor de Siscar y Teresa de Híjar, de quienes nos ocuparemos más adelante, también intervienen en la Huesca bajomedieval; o el testimonio recogido en los Libros de Actas de la ciudad correspondiente a los años 1474 y 1475 de la hija de Martín de Gabarre, de quien leemos su alegato de defensa por las promesas intercambiadas entre ella y Tomás de Agudo, que son claro ejemplo de la naturaleza difusa y algo caótica del matrimonio en el Cuatrocientos.

A lo largo del periodo estudiado, la Iglesia tratará de imponer su sanción al proceso mediante la solemnización del matrimonio en la faz de la iglesia. Algunos de los enlaces celebrados cumplían a la perfección con los pasos establecidos, como el de Águeda de Rajadel, quien no en vano era sobrina del chantre de la catedral de Huesca, y el guantero Nicolás de Cardejón, cuyos capítulos, dictados en 1481, bien podrían servir como modelo matrimonial ideal.

A cualquier escala social «colocarse» en un buen matrimonio, utilizando la expresión de la época, era una cuestión clave para el desarrollo vital de las mujeres, por lo que vieron, las de mayor rango, cómo su entorno elegía sus parejas por ellas, llegando a condicionarles incluso la recepción de la herencia a que contrajesen matrimonio a juicio de los albaceas y ejecutores testamentarios, fenómeno que se documenta asimismo en la Huesca de finales del Cuatrocientos. Pero además de las tres tipologías matrimoniales de las que la Tesis Doctoral presenta ejemplos suficientes y diversos, los hombres y mujeres de finales de la Edad Media desarrollaron otras formas de convivencia, como el amancebamiento, que queda representado a través del contrato que firmaron Nadal Durit y Teresa de Salcedo en 1453, único documento de este tipo que he hallado entre los conservados en los fondos notariales oscenses.

En este capítulo también se estudian las fiestas de boda, un momento culminante y cargado de significado en la vida de muchas mujeres medievales, que supone además una ruptura del orden cotidiano y en el que ellas cuentan 
con un protagonismo indiscutible. Previamente a la celebración y la fiesta, madres, padres, abuelos y familiares o, en su defecto, tutores y tutoras, habían invertido tiempo y esfuerzo en concertar los matrimonios. Los ejemplos son múltiples: desde la humilde Antona de Anciniello, una viuda que en 1477 ruega por carta al ciudadano Pedro Palacio que negocie el matrimonio de su hijo «como si fuera pariente», hasta los calculados movimientos de las elites urbanas, como las previsiones de Martín de Lacambra, destacado ciudadano oscense que ocupó diversos cargos en las décadas centrales del Cuatrocientos, para sus hijas o los buenos enlaces que las judeoconversas diseñaron para las suyas, emparentando con los grupos privilegiados de la ciudad de Huesca, son objeto de estudio en esta Tesis. Las celebraciones, en ocasiones masivas y excesivas, y las aportaciones familiares, estipuladas en acuerdos y capitulaciones, dejan igualmente su rastro en la documentación notarial y legal, como ocurre, por ejemplo, en las Ordenanzas de Huesca de 1285, en las que se delimita claramente y con gran detalle qué es y qué no es una celebración adecuada, quién tiene derecho a participar de la misma y cuáles son los regalos que invitados y contrayentes pueden intercambiar.

De entre los muchos documentos que se refieren en estos sub-apartados del trabajo posee gran interés salvoconducto ofrecido por las autoridades oscenses a una novia - Beatriz de Oriz- y su familia, originarios de Lérida, quienes debían desplazarse hasta Huesca para celebrar una solemnización y fiesta de boda en un momento en el que la ciudad estaba inmersa en luchas de banderías. El matrimonio se había celebrado por poderes en los respectivos lugares de origen de los novios, pero era necesaria la presencia de la novia en la ciudad para que los recién casados confirmaran la unión mediante cópula carnal. Estos y otros elementos permiten observar y describir la cotidianeidad de las oscenses de finales de la Edad Media, y ponerla en relación con las de las mujeres de otros espacios peninsulares, tanto a través de las fuentes documentales como de las literarias o iconográficas, de entre las que destacan, por ejemplo, las descripciones de las bodas en Los hechos del Condestable don Miguel Lucas de Iranzo, celebradas en 1457.

Pero no puede olvidarse que el matrimonio es, esencialmente, un contrato que da comienzo a una sociedad con intereses económicos, cuestión que se refleja en las capitulaciones cristianas y las ketubás judías. De nuevo aquí se observan tendencias comunes en las mujeres de las tres religiones, y es que, de una forma u otra, los acuerdos matrimoniales que firman tienen por objeto su protección. La fórmula «ni decebida ni enganyada» de los documentos cristia- 
nos, o las reclamaciones patrimoniales que moras como Yel Marguán o Zorate Alguazir realizaron ante notario a finales del Cuatrocientos, refuerzan la idea de protección de las mujeres, siempre, eso sí, en la medida de las posibilidades que ofrece el marco legal de cada religión y contando con lo que hemos dado en llamar las transferencias propias de la convivencia. Los archivos oscenses custodiaban centenares de capitulaciones matrimoniales cristianas (hemos analizado unas 250 para este trabajo) algunas de las cuales se incluyen en el apéndice. Pero además la investigación nos ha llevado hasta otros documentos tan interesantes como la reclamación de la moza de Sancho de Aso, quien en 1486, para proteger su honor y demostrar su virtud solicita ser esperimentada por una madrina (es decir, examinada ginecológicamente por una partera), puesto que ella, aseguraba, no había mantenido relaciones sexuales con el joven que la pretendía, no había transgredido la norma y no quería que su fama se viera afectada.

De igual manera, al estudiar las capitulaciones de las mujeres cristianas se advierten las estrategias matrimoniales y patrimoniales, así como un modelo femenino de comportamiento diferente, al que la documentación oscense denomina «señora mayora» - y que en otros lugares del Reino, como Zaragoza, adopta la denominación de señora poderosa- (García, 1990). Este vocablo describe a una mujer, generalmente viuda, a la que se le confiere capacidad para administrar bienes más allá de lo que le permite la normativa foral que rige la mayoría de las uniones en el Aragón bajomedieval, entroncando, en parte, con la idea altoaragonesa de Casa, una institución que agrupaba una serie de bienes bajo reglas y dominios específicos y que podía quedar en manos femeninas si el grupo familiar o las circunstancias así lo indicaban. Son muchas las cristianas $-\mathrm{e}$ incluso alguna judía - , que alcanzan esa categoría de «señoras mayoras» de una serie de bienes (tiendas, negocios o empresas familiares) para los que generalmente sus maridos les conceden plenos poderes y total capacidad de administración a perpetuidad, sin importar, como ocurría en la viudedad foral, si casaban de nuevo o no. En las capitulaciones matrimoniales en las que aparecen mencionadas estas mujeres poderosas lo más habitual es que se haya pactado una cohabitación entre los recién casados y la madre de uno de ellos, bien fuera porque el objeto de herencia, la casa familiar, era compartida, o bien porque la madre y señora mayora administraba una tienda o se dedicaba a un oficio concreto que pensaba seguir ejerciendo hasta el final de sus días. Esta particular denominación de «señora mayora», se documenta, en ocasiones, en donaciones inter vivos, testamentos o renuncias de bienes -o de su administración - (Pérez, 2015: 182-192). Sirve como ejemplo la capitulación 
matrimonial de Pedro Lores y María Sopena. En ella, la viuda María López de Rasal, madre de Pedro, cede a su hijo la mitad de todos sus bienes, con la condición de que ella quede como señora de la otra mitad:

Primerament traye el dicho Pedro Lopes en ayuda e socorro del dito su matrimonio con la dicha Maria Sopenna, sposa suya, son a saber la mitat de todos los bienes que los ditos Maria de Rasal, madre suya, et Johan de Lores, ermano suyo, mobles e sedientes e por si movientes, nonbres, dreytos e acciones a ellyos e qualquiere dellyos pertenecientes en qualquiere manera o tal manera e condicion que la dita Maria de Rasal, madre suya, quede senyora e mayora de la dita mitat de los ditos bienes e acciones durant tiempo de su bida e no mas, con la qual condicion que sean el dito Pedro, sposo sobredito, que la dita Maria Sopenna, sposa suya, aya aquellya part e drecho que muxer deve aver en bienes esdevenidos de matrimonio e asignados e traydos segunt los fueros del regno de Aragon, los quales bienes le dan e asignan luego depresent los ditos Maria de Rasal e Johan de Lores. ${ }^{4}$

Respecto a las mujeres de las minorías existe una diferencia esencial con las cristianas, que es la posibilidad de repudio y divorcio que tanto judías como musulmanas podían sufrir por imperativo legal, ya que no estaba en su mano tomar ninguna de estas dos decisiones. Zorate Alguazir y Alí del Pex, habitantes de la ciudad de Huesca, deshicieron su matrimonio, cuestión que podemos probar gracias a un documento de un notario cristiano de 1486. En él, los hasta entonces cónyuges firman una carta de comanda que certifica su separación y detalla las operaciones económicas que ésta tiene como consecuencia, mediante la que Zorate recibe todos los bienes que había aportado al contraer matrimonio. En la Tesis Doctoral se estudian además otras soluciones a la convivencia, como el levirato, del que se incluye un ejemplo de 1445 publicado por Eugenio Benedicto que consideramos relevante para su conjunto, puesto que según algunos investigadores era una práctica poco frecuente en Sefarad. Entre las cristianas contamos con un documento excepcional, una carta de separación de cuerpos entre Toda de Rosiello y Pedro de Longares otorgada en la década de los setenta del siglo xv. La vida de ambos, a decir del testimonio de amigos y parientes, corría grave peligro, pues los malos tratos eran constantes y mutuos, por lo que se les concedió una suerte de divorcio en forma de separación y resolución de reparto de bienes como si hubieran enviudado, y así se hace constar en la sentencia que también se incluye en el apéndice. 
Las disposiciones económicas del matrimonio de las cristianas en el Aragón bajomedieval, marcadas por los Fueros y Observancias del Reino, tienen como consecuencia fundamental y diferenciadora la viudedad foral, una institución nacida con la Compilación de Huesca de 1247 que coloca a las viudas aragonesas en una situación sustancialmente diferente - podría decirse mejor- que la de sus homólogas en otros reinos peninsulares. Ls viudas, pues, independientemente de su religión, son quienes más presencia tienen en la documentación oscense bajomedieval, tanto notarial como municipal o judicial. Su particular estatus les confiere capacidad de gestión y las habilita para intervenir y participar de actividades económicas y procesos judiciales, lo que incrementa su visibilidad.

La viudedad foral, en resumida explicación, permite que el cónyuge supérstite disfrute de los bienes privativos del premuerto y de la parte que le correspondía también en los bienes comunes, que se añaden a los que ya poseía como propios (García, 2005: 155-176). Podía, igualmente, renunciarse a ese derecho, y en los matrimonios de las clases más capaces económicamente suele ser una de las condiciones estipuladas en las capitulaciones. También cabía la posibilidad de que la madre viuda renunciara a su derecho al contraer matrimonio alguno de sus hijos, como hizo en 1476 María de Alcolea, madre del escudero Blasco de Azlor, para traspasarle el patrimonio. Así, muchas oscenses hubieron de gestionar capitales y negocios mientras se ocupaban, cómo no, del cuidado de sus hijos y pupilos, puesto que era frecuente que algunas viudas, en calidad de familiares o de personas de buena consideración, fueran nombradas tutoras y curadoras de niños y niñas huérfanas y desamparadas. Otras, por su parte, podían ser designadas propietarias de bienes inmuebles de los que habían de tomar posesión, como hicieron, por ejemplo, las magníficas Aldonza de Gurrea y su hija, María López de Gurrea, con el castillo y lugar de Cuarte mediante su procurador, el ciudadano Martín de la Cambra, en 1479. Muzate Xidet, viuda mora, también hubo de tomar posesión mediante procurador de una tienda sita en la plaza de Florién de la ciudad de Huesca, tarea que encomendó a Zaat de Albalentia en 1474, por citar algunos de los ejemplos detallados en la Tesis Doctoral.

En el capítulo dedicado a las viudas y mujeres solas optamos por trazar una decena de historias de vida. Estas biografías nacen de la reconstrucción documental de la trayectoria de algunas de las viudas más influyentes de la Huesca de finales del Cuatrocientos, gracias, fundamentalmente, a los documentos generados por sus operaciones económicas. Las actividades económi- 
cas de las viudas judías y musulmanas también son objeto de nuestra atención en este apartado: ejercen como procuradoras de familiares y amigos, bien de otras mujeres, bien de varones de su entorno; resuelven lo relacionado con los negocios que habían heredado y recibido al cambiar de estado, como los préstamos que el viudo de Muzate Pridet, Abraham de Marguán, había dejado sin cobrar en vida y que reclama ella en 1471, o las numerosas procuraciones que Astruga Darsán lleva a cabo para otras judías de su entorno, a las que le unían, en ocasiones, vínculos familiares, hacia finales de la centuria.

Una de las trayectorias más destacadas es la de la conversa Violant de Alcolea, una de las mujeres más poderosas de la Huesca de finales del Cuatrocientos, quien tras enviudar del jurista y ciudadano Manuel Lunel, comienza a aparecer de manera constante en la documentación notarial oscense con una estrategia clara, pues es una hábil mujer de negocios: se dedica a la compraventa y el crédito, dos actividades muy lucrativas que le permitirán, con los beneficios generados en algo menos de diez años, retirarse de la esfera pública, como puede inferirse de la documentación notarial. La sociedad bajomedieval asumía el crédito como un recurso inevitable y cotidiano, y algunas viudas como Violant de Alcolea podían camuflar la prohibida pero segura usura a la que se dedicaban mediante las numerosas comandas que hallamos a su nombre. Las operaciones económicas llevadas a cabo por Violant en sus primeros años de viudez, entre 1476 y 1486, le sirven para organizar su patrimonio e incrementarlo notablemente. Dado su carácter judeoconverso, es frecuente además verla negociar con hombres y mujeres de la minoría semita, con quienes interactúa a lo largo de toda su vida. Su comportamiento más habitual consistía en adquirir una propiedad (desde casas enteras hasta porciones de campos, llamadas fajas en la documentación notarial) y, acto seguido, alquilarla a los que hasta entonces habían sido sus propietarios, quienes se la habían vendido, probablemente, por una necesidad acuciante de liquidez. La viuda está al corriente del pago de sus treudos, cantidades para las que redacta numerosos albaranes, puesto que de no ser así se arriesga a perder su viudedad, como se estipulaba en los Fueros, y nombra además procuradores y procuradoras, normalmente miembros de su familia, que la ayudarán a gestionar su extenso patrimonio en lugares o momentos puntuales.

Otra de sus ocupaciones, al menos según lo que muestran los registros notariales, era el préstamo de efectivo en cuantías diversas. Violant de Alcolea compra y vende deuda de particulares o de instituciones, y a lo largo de los documentos en los que aparece hasta 1496, fecha probable de su muerte, son 
abundantes las cartas de comanda en las que un particular o institución se compromete a devolverle una cantidad de dinero en un plazo no muy amplio. Es una práctica que, podríamos decir, hereda de su marido, pues estando viuda cancela algunos préstamos que había gestionado él. Ella parece ser una fuente de crédito rápido para aquellos que están de paso por la ciudad, y presta a vecinos de otras poblaciones del entorno, de lo que se deduce que su fama como prestamista era conocida en toda la ciudad e incluso en los aledaños (Pérez, 2017).

Hacia el final de sus días, Violant de Alcolea redactó, al menos, dos testamentos y un codicilo. El primero de los testamentos está rubricado en 1489, y el último, aunque conservado en el protocolo correspondiente a los años 14801484, está fechado claramente al comienzo en 1496. Nuestra hipótesis de la mala colocación del documento, en un protocolo de un año erróneo, se sustenta en datos indirectos como la aparición de una «Violant, viuda» en el Fogaje de 1495, momento en el que la ciudad contaba con 616 fuegos y que comenzó a inventariarse por la carrera de Salas, una de las vías principales de la urbe (Serrano, 1997: 149). Ambos testamentos difieren de manera sustancial, pues en el primero los herederos universales son sus sobrinos, Blasco de Azlor y micer Johan Serra - a los que ella llama nietos-, y, en el último, el destinatario y ejecutor es el Hospital de Nuestra Señora de la Esperanza de Huesca. Cabe la posibilidad de que en los siete años que separan ambos documentos las circunstancias de los familiares de Violant se modificasen. El objetivo esencial es que su vida ultraterrena y el cuidado de su alma se financien de manera suficiente, por lo que dispone importantes cantidades de dinero para los frailes predicadores, donde se enterrará, para el monasterio del Carmen de Huesca y para otros lugares como Santa María de Salas. De igual manera, Violant, que no tuvo hijos -o no le sobrevivieron-, destina gran parte de su capital a obras pías, y en ambos testamentos se muestra su profunda espiritualidad y su particular devoción por la Virgen María - que si bien parece real no está exenta de dudas por la naturaleza conversa de nuestra protagonista-.

Las biografías restantes presentan trayectorias que repiten los patrones de mujeres poderosas - aunque a menor escala que Violante de Alcolea-, pero igualmente preparadas para gestionar sus casas y sus negocios, y con voluntad y autoridad suficiente para hacerlo. Entre ellas se cuentan las historias de Sancha de Puértolas, viuda desde 1454, quien se hizo cargo de la tienda de telas de su segundo marido; María Pérez de Bordalba, que ejerció como procuradora de sus cuñadas, las Alcolea, durante las décadas de los sesenta, setenta y ochenta del siglo xv; y Francisca de Pueyo, viuda del notario Blasco 
Colduras, muerto en 1486, así como de la judía Soli Alfrangil y la musulmana Muzate Pridet, quien, como se ha señalado con anterioridad, reclamó lo que le pertenecía, según las leyes territoriales aragonesas, de los bienes del que había sido su marido, Abraham de Marguán.

El quinto capítulo de la Tesis Doctoral está dedicado a la actividad femenina en el mundo laboral y presenta una estructura diferente al resto de la obra. Pese a los esfuerzos por analizar de manera conjunta, - en ese gendered contex del que hacíamos mención al inicio-, a las mujeres de las tres religiones, las sustanciales diferencias normativas y legales nos llevaban a una aproximación diferenciada en algunas de las cuestiones planteadas en los capítulos iniciales, como la educación de niñas y jóvenes o el matrimonio. Sin embargo, la actividad laboral femenina permite un estudio de conjunto, estructurado en torno a los ámbitos de actuación, los oficios y ocupaciones de las mujeres, sin las divisiones religiosas preexistentes. Así pues, hemos generado siete categorías diferentes, desde las empleadas en el servicio doméstico hasta las trabajadoras de mayor cualificación, como parteras, nodrizas, árbitras, tasadoras o procuradoras, sin dejar de lado a aquellas instaladas en los márgenes de la sociedad, como las prostitutas y alcahuetas, para el análisis de esta realidad.

Muchas de las jóvenes oscenses empleadas en el servicio doméstico, una ocupación al alcance de mujeres de baja extracción social, fundamentalmente cristianas y musulmanas, accedían mediante ese trabajo a los conocimientos y habilidades necesarias para llevar una casa y alcanzar una dote suficiente para contraer matrimonio. Además, permitía a las familias, en origen, eliminar una carga y garantizar el futuro de sus descendientes, así como mejorar la economía familiar, por lo que era una solución común y abundante. A través de las llamadas firmas de moza, un documento de naturaleza indefinida, podemos establecer pautas de comportamiento y extraer los datos esenciales del proceso: las partes involucradas, la duración del contrato y el salario y formas de pago del mismo. Generalmente, cuanto más lejano era el origen de la moza empleada, más larga la duración del contrato. De igual manera, se aprecia en la documentación la diferencia entre mozas serviciales y criadas, siendo estas últimas tratadas de manera desigual, casi como prohijadas, que las primeras, meras empleadas del hogar o el negocio familiar en el que se incorporaban.

De la observación de las mujeres que trabajan en el sector se extraen además, dos conclusiones interesantes. Por un lado, las mujeres musulmanas, empleadas frecuentemente en el servicio doméstico en Huesca, no tenían reconocida en la legislación su capacidad de ganar un salario, y es común que en sus 
firmas sean los familiares varones quienes recojan la soldada al comienzo, en el mismo momento de la firma del contrato, aunque autoras como Shatzmiller reconocen que cuando los muftíes tienen que resolver cuestiones económicas de esta índole, terminan por reconocer la capacidad de las mujeres de manejar sus ingresos (Shatzmiler, 1997: 201-202). Por el otro, la capacidad de las mujeres aragonesas de casi cualquier estamento y condición para reclamar lo que les pertenecía por derecho ante los tribunales y cortes de justicia se pone de manifiesto con reclamaciones como la de María de Latintas, quien en 1463 inició una causa contra el mercader Martín de Bolea, su empleador, por una deuda que éste había contraído con ella, pues no le había entregado setenta sueldos, unas calzas y unos zapatos que se le adeudaban de su soldada. La moza presentó incluso testimonios a su favor en la causa, como el de Andrina, la mujer de Bernat de Bello, quien relataba así, como se recoge en los Libros de Actas de la ciudad, lo ocurrido:

Deposo e dixo que ella sabia que quando partio de su casa contoron la dita Maria e el dito Martin de Bolea e todo conto pasado quedo quel dito Martin le avia de dar XXXX sueldos e tres pares de calcas e hun par de capatos e $\mathrm{X}$ sueldos contantes. En aquestion e apres juro la dita Maria que pas vio conto present la muller de Bernart de Belloch e resto que pagadas las especias e el mege resto que lavia de dar XXXX sueldos, tres pares de calcas e hun par de capatos e encara $\mathrm{X}$ sueldos que costavan que estaban en questiones. $^{5}$

Los trabajos relacionados con la vida y la muerte, desde comadronas y nodrizas hasta las hospitaleras o defunteras, es decir, las encargadas de cuidar enfermos y/o preparar los cadáveres para su entierro y organizar funerales, son también ocupaciones feminizadas, bien fuera por necesidad o tradición. De esta cuestión, la realidad oscense del Cuatrocientos ofrece una muestra pequeña pero significativa. La presencia femenina en todo lo relacionado con los cuidados del cuerpo y la salud es constante e innegable. Tal y como ha señalado Montserrat Cabré en muchos de sus trabajos, la cosmética y las prácticas médicas y terapéuticas constituyeron una importante rama de saber femenino, que se transmitía de madres a hijas generación tras generación, y que en ocasiones se ponía por escrito, bien en forma de compilaciones, bien en forma de breves notas, como la oración contra la fiebre malediza y una receta para madurar y obrir que hallé entre la documentación oscense, en las guardas de 
los protocolos notariales (Cabré, 2000; 2005). Atender los partos o examinar el cuerpo de sus congéneres son dos de las ocupaciones para las que las mujeres están preparadas y que ejercen de forma indudable.

Otro de los sectores con notable presencia femenina es el de alimentación, especialmente todo lo relacionado con la manufactura y venta de pan, donde se documenta una numerosa cantidad de mujeres ocupando puestos en toda la escala de responsabilidad, desde el amasado, el horneado o la venta, además de las dueñas de hornos de la ciudad. Dada la importancia fundamental de este alimento en la dieta, y las etapas de carestía que la ciudad había atravesado en las décadas anteriores, la normativa municipal regula el proceso de fabricación y venta del pan, lo que genera, en ocasiones, reclamaciones ante los jurados de la ciudad. En una de las declaraciones por un conflicto generado por el comportamiento de Pedro Cavero y Juana Domenech declara ante los oficiales municipales Simona de Bolea, quien en 1476 describe el proceso, y en cuyo relato la presencia femenina es significativa (Pérez, 2015: 349. AP. DOC. 51).

Comprar y vender son tareas vinculadas igualmente a lo femenino. Desde las grandes mercaderas como Madona Angelina de Colonia, quien desarrolló la mayor parte de su actividad en la primera mitad del siglo xv, (Sesma, 2005: 31-32) a ejemplos más humildes, como Marién de Marguán y Marién Ben Rala, que formaron parte de compañías mercantiles a finales del Cuatrocientos en Huesca, encontramos mujeres que gestionaron pequeños negocios, como la tienda de ropa para criaturas de Jayma Nasarre, o la farmacia de Gracia Liçagaray, así como las tiendas de Gayate de Menestral o Fátima de Alfarrán, dos mujeres musulmanas que poseían y alquilaban espacios comerciales. Muchas oscenses, tanto cristianas, como judías, como musulmanas, manejaron sus propios negocios, especialmente durante su viudez, amparadas en el marco legal foral.

Por otro lado, uno de los descubrimientos más interesantes de esta Tesis Doctoral es la certificación documental de que las mujeres conocen el valor y el precio de los objetos, y que son bien consideradas por ello. Algunas de ellas, como ocurría en la Alemania de comienzos del siglo xvi (Wiesner, 1990), ejercieron como tasadoras de bienes en operaciones de compraventa para las que eran convocadas, así como en la preparación de ajuares y regalos de novia o en la confección de inventarios. Estas tasadoras, de las que dimos noticia hace unos años (Pérez, 2013b), se ponen en relación con las otras mujeres que conocen el valor de las cosas, y de quienes se esperan juicios justos y ponderados: las árbitras, arbitradoras y amigables componedoras. En la ciudad de 
Huesca encontramos, en las décadas de los ochenta y noventa del siglo XV a dos mujeres, Leonor de Siscar y Teresa de Híjar que ejercieron este oficio que les conecta a otras mujeres aragonesas bajomedievales, a quienes investigó y describió María del Carmen García Herrero (García, 2005: 353-383). Por último, pero no menos importante, en estos trabajos en los que participan las mujeres que conocen el valor de las cosas, como se denomina al epígrafe en la Tesis Doctoral, hemos decidido incluir a las procuradoras, ocupación que de nuevo contiene representación de féminas de las tres culturas. A finales de la Edad Media en Huesca no resultaba extraño que las mujeres actuasen como procuradoras de sus familiares o de personas cercanas de su entorno. Muchas eran nombradas para recaudar pagos o deudas pendientes, así como para llevar a cabo ventas de bienes muebles e inmuebles. Nos sirve como ejemplo el caso de Leonor de Pomar, quien en 1480 cuando hubo de cobrar unos bienes que le debía Catalina, mayordombresa de Martín de Pomar, nombró procuradora suya a Guallarda de Labau, la mujer de Martín, «pora demandar, haver, recebir e cobrar de Catalina, mayordombresa del senyor don Johan Perez de Ayerbe, una toca e hun tocaxo que tiene enpenyada por quatro carlines e de Johana Sese media toca e hun collet por entallar lental e atorgar haver recebido a pleytos con poder de substituir e jurar etcetera» (Pérez, 2015: 374). Las procuradoras también podían ejercer como albaceas o ejecutoras testamentarias, como hicieron María de Alcalá y Elvira de Tarazona, a quien la primera encomendó el cumplimiento de sus últimas voluntades en 1452. Por su parte, entre las minorías de la ciudad, ésta era también una ocupación común. Çuleyman de Albaho, notario musulmán establecido en Valencia, nombró procuradora suya a su hermana Gayate, que vivía en Huesca. Y en 1458, Gento Levi, habitante de presente en Huesca, nombró diversos procuradores para sus asuntos, entre los que se contaba su mujer, Dueña Dalmachugui.

El último de los epígrafes se dedica a las trabajadoras sin cualificación que se sitúan en los márgenes de la sociedad, fundamentalmente prostitutas y alcahuetas. Ambos grupos son estudiados a través de documentos relacionados con el ejercicio de su trabajo, en los que se menciona y ubica el burdel de Huesca, así como mediante noticias sobre relaciones mixtas entre hombres musulmanes y prostitutas cristianas, comportamiento que se perseguía incansablemente por parte de las autoridades municipales. Entre las noticias relacionadas con prostitución y alcahuetería encontramos también denuncias sobre tráfico de personas, como la operación que Teresa, una alcahueta, llevó a cabo con Franci Torén, quien intentaba prostituir a su nieta con un grupo de curas en 1472. En aquel año, el notario del Concejo, Antón de Bonifant, Pedro y Antón Carnoy 
declaraban que una mujer llamada Teresa, casada con Alfonso de Tuernas, era «alcagueta verdadera», y ofrecía a su nieta a uno - o varios- capellanes a los que habían visto besarla. Unos años antes el mismo notario recoge una noticia de cariz similar, en la que Franci Toren quería amigar a su nieta con alguien para saldar una deuda, pero le aconsejaron «que no vendiese su sangre». Franci trajo de Sigena a su casa de Huesca a una nieta suya llamada Ysabel, a la que según el relato de Pere Ponz pretendía casar. Sin embargo, otras noticias apuntan que la muchacha había sido vendida a un tal Ereber por tiempo de dos años y precio de 200 sueldos, aunque Franci tenía que tenerla en su casa. En la información, finalmente, se recoge la voz de Ysabel, quien asegura que «devant el dito su tio dizia la dita Ysabel: "mas queria que me dasez hun marido por dolient que fuese que no ser amiga de ninguno". E a oydo dezir que hun dia armo la ballesta por matar a Ereber, e que ella le tiro el pasador e sende muyto escalancados» (Pérez, 2015: 381)

La religiosidad femenina es el último de los ejes temáticos de Cristianas, judías y musulmanas en la ciudad de Huesca a finales de la Edad Media, y los más de 300 testamentos que he consultado, la fuente primordial que permite conocer tanto la presencia y representatividad de las mujeres en los momentos finales de la vida como parte de su pensamiento y creencias.

Dictar testamento era una práctica habitual entre las mujeres de toda clase y condición y era, además, casi una obligación legal y moral, puesto que los Fueros, Usos y Costumbres de Aragón así lo indicaban y regulaban mediante el fuero De Testamentis (Savall y Penen, 1991: I, 240). La testadora debía ordenar sus bienes en la mejor forma y manera posibles, distribuyéndolos con cuidado y atención, para evitar posteriores enfrentamientos entre sus herederos. Es por eso por lo que estos documentos permiten conocer algunas de las prácticas y focos devocionales y funerarios de las cristianas oscenses, desde la elección del lugar de sepultura y los aditamentos de la misma a la celebración de misas pro remedio animae, con sus lógicas de acumulación y repetición, que todas ellas encargaban en la medida de sus capacidades económicas.

De otro lado, nada es casual en la Edad Media, y mucho menos en lo que toca a la muerte y la vida ultraterrena. La mayoría de las oscenses deseaban ser inhumadas junto a sus seres queridos, y si era posible elegían como lugar de descanso eterno un espacio privilegiado dentro del recinto sacro. Un lugar óptimo era el espacio adyacente a la pila bautismal, como solicitaron en sus testamentos datados en 1486 y 1491 respectivamente Blasco Colduras y Francisca de Pueyo, ubicación que, a ojos de los hombres y mujeres bajome- 
dievales, evitaba las penas infernales y garantizaba un mejor y más rápido acceso al Paraíso. Se ha prestado igualmente especial atención a los encargos de aniversarios y capellanías, que permiten estimar la capacidad económica de las fallecidas, así como a fenómenos tan interesantes y aún inexplicados como los treintanarios de San Amador, $\mathrm{u}$ otras costumbres menos frecuentes como los banquetes funerarios. La Tesis aborda otras cuestiones aparentemente menores, como la importancia de la luz y el sonido o las ofrendas y procesiones funerarias. A través de las donaciones testamentarias también se reflexiona en torno a la transmisión de bienes simbólicos y los afectos de las testadoras. Las ropas y vestimentas eran bienes muy preciados en la Baja Edad Media, y en el caso de las de luto, que servían para expresar duelo, se llevaban además para demostrar cierta posición social y capacidad económica, como ocurría con el paño de Orienza, o bien eran traspasadas de un usuario a otro, incrementando así su capital simbólico.

El mapa devocional oscense pivotaba en torno a dos grandes ejes. Por un lado, los conventos de las órdenes mendicantes, especialmente los franciscanos, y, por el otro, las grandes iglesias y parroquias de la ciudad, en concreto la Catedral, San Pedro el Viejo y San Lorenzo, los centros que con más demandas de inhumación y misas cuentan en la documentación analizada. Otros emplazamientos de especial devoción entre las oscenses eran Santa María de Salas, Santa María y San Miguel de Almudévar o Santa Quiteria del Monasterio del Carmen, a tenor del número de misas encargadas en los citados lugares. Así mismo, al igual que en otros lugares, los testamentos de las aragonesas sirven para descubrir los legados píos y las instituciones caritativas beneficiadas por las cristianas, que en el caso de Huesca eran, fundamentalmente, el Hospital de Nuestra Señora de la Esperanza y la Almosna, y para observar las redes de solidaridad femenina: las más poderosas dotaban con generosidad a las necesitadas que les rodeaban, bien con cantidades significativas de dinero, bien con bienes materiales como joyas y ropas.

Otro de los aspectos más interesantes de la religiosidad femenina bajomedieval, y al que nos hemos referido en trabajos previos a esta Tesis Doctoral es el mecenazgo, una práctica que se situaba a medio camino entre la piedad y el deseo de adquirir notoriedad y fama ultraterrena mediante la comisión y financiación de obras artísticas, que posibilita conocer tanto la espiritualidad de las mujeres como su forma de ver y estar en el mundo (Pérez, 2013c). Algunas oscenses invirtieron una parte de su capital para hacer perdurar su memoria mediante la financiación de obras de arte, fundamentalmente retablos. 
El mecenazgo no es una práctica exclusivamente femenina, pero el empeño de algunas mujeres por hacer destacar su individualidad y su linaje mediante las obras artísticas que comisionaban es significativo. Lo entendemos, además, como una forma más de participar en la vida pública y una alternativa para la proclamación de la propia identidad femenina. Los contratos de retablos que he hallado entre los fondos notariales, además de los testimonios iconográficos que han pervivido, tanto en Huesca como en otros puntos del Reino de Aragón, permiten presentar un panorama actualizado y necesario para reconstruir tanto la identidad como la devoción de muchas de ellas. De todos ellos se da buena cuenta en las páginas de la Tesis Doctoral.

Por último, cabe señalar que estudiar en la medida de las posibilidades de las fuentes documentales e iconográficas la religiosidad de las mujeres de las minorías, especialmente de las judeoconversas, es un aspecto que garantiza profundizar indudablemente en el conocimiento de su cotidianeidad, sus relaciones inter religiosas y sus trayectorias y estrategias de vida. Las conversas oscenses mantenían, más o menos veladamente, los ritos y prácticas religiosas semitas, lo que supuso, para muchas de ellas, persecuciones, castigos y hasta la muerte. A ellas hemos dedicado trabajos complementarios a esta Tesis (Pérez, 2014), por lo que ahora nos centraremos en los testamentos de mujeres judías dictados ante notarios cristianos, una práctica poco común, pues, de un lado, los judíos no estaban obligados a dictar testamento, y, del otro, es significativo que quieran hacerlo ante cristianos - probablemente conversos-. Se han conservado cinco testamentos de judías oscenses, tras cuya lectura pueden extraerse las siguientes conclusiones: existía en Huesca un fossar de los judíos, y es allí donde muchas de ellas quieren ser inhumadas; son conscientes de la finitud de la vida y de la hora incierta de la muerte, y manifiestan, como las cristianas, su preocupación ante este momento; les concierne también su sepultura y alguna de ellas reserva parte de sus bienes para la confección de una lápida. Entre las judías las postrimerías de la vida se presentan como un momento óptimo para demostrar afectos y cuidar a las personas del entorno, siendo muy relevante la permanencia en la fe semita o la conversión al cristianismo, como ocurrió con los descendientes de algunas de ellas; de nuevo las ropas y joyas, objetos de valor material y simbólico, se ven dotadas de una relevancia notable en el reparto de bienes que consignan los testamentos. Por último, podemos señalar que las judías que testan pretenden mejorar la vida de quienes les rodean evitando conflictos de un lado y concediendo generosas lejas a las instituciones asistenciales judías del otro. 
El papel predominante desarrollado por las mujeres en las ceremonias del duelo y en las demostraciones públicas de dolor, así como la fuerte presencia de una cultura de lo macabro en la Baja Edad Media peninsular, les concede un lugar destacado en los momentos finales de la vida, que los legisladores trataron de regular sin demasiado éxito en la Huesca de finales de la Edad Media.

Para concluir este texto tan sólo querría citar un párrafo de una de las múltiples lecturas de estos años en los que he estado dedicada a la investigación y la redacción de esta Tesis Doctoral. En 1960, en el prólogo de la reedición de una de sus grandes obras, El niño y la vida familiar en el Antiguo Régimen, Philippe Ariès relataba de esta forma tan acertada la sensación que la doctoranda percibe cuando ve, o más bien intuye, el final de su trabajo, la culminación de sus hipótesis. Tras años de revisar documentación, buscar y leer la bibliografía, siempre inabarcable, de conversaciones, viajes e intuiciones sobre la Huesca bajomedieval, las palabras de Ariès describen a la perfección las experiencias vividas en ese proceso:

\footnotetext{
Dicen que los árboles no dejan ver el bosque, pero el período más interesante de la investigación sigue siendo el momento en que el historiador comienza a tener una visión de conjunto, cuando todavía no se ha disipado la bruma que cubre los horizontes lejanos, de suerte que no se ha distanciado de los detalles de los documentos en bruto y que éstos conservan aún toda su lozanía. Su mayor mérito no es quizás tanto el de defender una tesis como el de comunicar a sus lectores la satisfacción de su hallazgo; el de sensibilizarlos, como lo ha sido él mismo, a los colores y a los senderos de lo desconocido (Ariès, 1987: 9).
}

Sensibilizar es, a mi entender, la palabra clave de este fragmento. Lo que cualquier autora desea conseguir con su investigación es hacer partícipes a los y las hipotéticas lectoras, bien sean investigadoras, bien público generalista, de sus hallazgos. En mi caso particular, dar a conocer la existencia, las relaciones, los trabajos y la mentalidad de las cristianas, judías y musulmanas que habitaron la ciudad de Huesca en el tránsito de la Edad Media a la Modernidad. Entenderlas, estudiarlas e incorporarlas a la vida, a la investigación y a la forma de mirar el pasado y el presente ha sido la motivación fundamental de este trabajo que, por otro lado, aspira a ser tan sólo una aportación más en el esfuerzo común de ampliar los senderos de lo desconocido y redescubrir a nuestras antepasadas, nuestra genealogía de mujeres poderosas, para escribir la historia lo más ajustada a la realidad posible, esto es, también en femenino. 


\section{Referencias bibliográficas}

ARIÈS, P. (1987), El niño y la vida familiar en el Antiguo Régimen, Madrid, Taurus. BAUMGARTEN, E. (2004), Mothers and Children. Jewish family life in Medieval Europe, Oxfordshire, Princeton University Press.

BAUMGARTEN, E. (2008) "A Separate people? Some directions for comparative research on medieval women", Journal of Medieval History , 34, 2, 212-228.

BENEDICTO, E. (2009), "Estampas de la vida judía y sus particularidades. Huesca, siglo xv", Sefarad, 69:2, 491-505.

CABRE I PAIRET, M. (2000), - “Nacer en relación”, en De dos en Dos. Las prácticas de creación y recreación de la vida y la convivencia humana, M. Beltrán y Tarres, C. Caballero Navas, M. Cabré i Pairet, M. Rivera Garretas, A. Vargas Martínez (eds.), Madrid, Horas y Horas 15-32.

CABRE I PAIRET, M. (2005), “"Como una madre, como una hija»: las mujeres y los cuidados de salud en la Baja Edad Media”, en Historia de las mujeres en España y América Latina, vol. I, De la Prehistoria a la Edad Media, I. Morant (dir.), M.A. Querol, C.Martínez, R. Pastor, A. Lavrin (coords.), Madrid, Cátedra, 637-658.

FUENTE PÉREZ, M. J. (2006), Velos y desvelos. Cristianas, musulmanas y judías en la España medieval, Madrid, La Esfera de los Libros.

Fueros, observancias y actos de Corte del Reino de Aragón,(1991), SAVALL DRONDA, P. y PENÉN DEBESA, S (eds.), Zaragoza, Ibercaja, 3 vols.

GARCÍA HERRERO, M.C. (1990), Las mujeres en Zaragoza en el siglo XV, Zaragoza, Ayuntamiento, 2 vols.

GARCÍA HERRERO, M.C. (2005), Del nacer y el vivir: fragmentos para una historia de la vida en la Baja Edad Media, Zaragoza, Institución Fernando el Católico.

GARCÍA HERRERO, M.C. y PÉREZ GALÁN, C. (2017), "Salaried Mothers: Breastfeeding and Rearing Infants in the Kingdom of Aragón", Early Modern Women: an Interdisciplinary Journal, 11, (en prensa).

GAUDEMET, J. (1993) El matrimonio en Occidente, Madrid, Taurus.

Hechos del Condestable don Miguel Lucas de Iranzo, (ed. de) DE MATA CARRIAZO, J. (1940), Madrid, Espasa Calpe.

IRANZO MUÑÍO, M.T. (2005), Élites políticas y gobierno urbano en Huesca en la Edad Media, Huesca, Crónica.

KLEIN, E. (2007), Jews, Christian Society and Royal Power in Medieval Barcelona, Michigan, The University of Michigan Press.

LERNER, G. (1993), The Creation of Feminist Consciousness: from the Middle Ages to Eighteen-Seventy, New York, Oxford University Press.

MARÍN, M. y DEGUILHEM, R. (2002), Writing the Feminine: Women in Arab Sources, London-New-York, I.B. Taurus Publishers. 
MARÍN, M. (2000), Estudios onomástico-biográficos de al-Ándalus. XI, Mujeres en AlÁndalus, Madrid, Consejo Superior de Investigaciones Científicas.

MARÍN, M. (2005), "Mujeres y vida familiar en al-Ándalus", Historia de las mujeres en España y América Latina, vol. I, De la Prehistoria a la Edad Media, en I. Morant (dir.), M.A. Querol, C.Martínez, R. Pastor, A. Lavrin (coords.), Madrid, Cátedra, 371-398.

PÉREZ GALÁN, C. (2013a), "Los grandes hospitales urbanos en Aragón en el siglo xv: Nuestra Señora de la Esperanza en Huesca y Nuestra Señora de Gracia en Zaragoza" en Assistenza e solidarieta' in Europa secc. XIII-XVIII / Social Assistance and Solidarity in Europe from the 13th to the 18th Centuries. Atti delle XLIV Settimana di Studi a cura di Francesco Ammannati, Florencia, Firenze University Press, 291-305.

PÉREZ GALÁN, C. (2013b) "En torno al valor de las cosas pequeñas: la tasación, un trabajo de mujeres en la ciudad de Huesca en la Baja Edad Media", en C. Villanueva, D. Reinaldos, J. Maíz, I. Calderón (eds.), Estudios recientes de jóvenes medievalistas. Lorca 2012, Centro de Estudios Medievales de la Universidad de Murcia, Ayuntamiento de Lorca, Lorcatur, Lorca, Taller del Tiempo S.A., Sociedad Española de Estudios Medievales, EDITUM, Universidad de Murcia, 127-135.

PÉREZ GALÁN, C. (2013c) “«Y en los escudos las armas de la senyora»: Mujeres y Mecenazgo. Retablos góticos en Aragón a finales de la Edad Media”, en J. Solórzano, B. Arízaga y A. Aguiar, (eds.), Ser Mujer en la Ciudad Medieval Europea. IX Encuentros Internacionales del Medievo 2012, Logroño, Instituto de Estudios Riojanos / Gobierno de la Rioja, 515-534.

PÉREZ GALÁN, C. (2014), "Religión, cultura y vida cotidiana de las oscenses procesadas por la Inquisición en la Baja Edad Media”, en M. C. García Herrero y C. Pérez Galán (coords.), Mujeres de la Edad Media: actividades políticas, socioeconómicas y culturales, Zaragoza, Institución Fernando el Católico, 217-240. PÉREZ GALÁN, C. (2017), “Judías y Conversas: relaciones de poder y solidaridad en el Aragón Bajomedieval”, Cuadernos de Estudios Gallegos (en prensa).

SERRANO MONTALVO, A. (1997), La población de Aragón según el fogaje de 1495. Vol. II, Sobrecullidas: fin de la de Calatayud, Tarazona, Huesca, Jaca, Aínsa, Barbastro y Ribagorza, Zaragoza, Institución Fernando el Católico-Gobierno de Aragón-Instituto Aragonés de Estadística.

SESMA MUÑOZ, J.A. (2005), Huesca, ciudad mercado de ámbito internacional en la Baja Edad Media según los registros de su aduana, Zaragoza, Universidad de Zaragoza, Dpto. de Historia Medieval y Grupo CEMA.

SHATZMILLER, M. (1994), Labour in the Islamic Medieval World, Leiden-New York, Brill. 
SHATZMILLER, M. (1997), "Women and Wage Labour in the Medieval Islamic West: Legal Issues in an Economic Context", Journal of Economic and Social History in the Orient, 40/2, 174-206.

VARELA, N. (2008), Feminismo para principiantes, Barcelona, Ediciones B.

WIESNER, M. E. (1990), ¿Buhoneras insignificantes o mercaderes esenciales? Las mujeres, el comercio y los servicios en Nuremberg durante la Edad Moderna", en J. Amelang y M. Nash (eds.), Historia y género. Las mujeres en la Europa Moderna y Contemporánea, Valencia, Edicions Alfons el Magnanim, 177-189.

WINER, R. L. (2006), Women, Wealth And Community in Perpignan, C. 1250-1300: Christians, Jews And Enslaved Muslims in a Medieval Mediterranean Town, Ashgate.

WOOLF, V. (2003), Un cuarto propio. Edición y traducción de María Milagros Rivera Garretas, Madrid, Horas y horas.

ZOMEÑO, A. (2000), Dote y matrimonio en al-Andalus y el norte de África. Estudio de la jurisprudencia islámica, Madrid, Consejo Superior de Investigaciones Científicas. 